University of Nebraska - Lincoln

DigitalCommons@University of Nebraska - Lincoln

Nebraska Cooperative Fish \& Wildlife Research Nebraska Cooperative Fish \& Wildlife Research Unit -- Staff Publications

2000

\title{
Parental Care and Clutch Sizes in North and South American Birds
}

Thomas E. Martin

U.S. Geological Survey, tom.martin@umontana.edu

P. R. Martin

University of Montana - Missoula

C. R. Olson

University of Montana - Missoula

B. J. Heidinger

University of Montana - Missoula

J. J. Fontaine

University of Montana - Missoula, jfontaine2@unl.edu

Follow this and additional works at: https://digitalcommons.unl.edu/ncfwrustaff

Part of the Other Environmental Sciences Commons

Martin, Thomas E.; Martin, P. R.; Olson, C. R.; Heidinger, B. J.; and Fontaine, J. J., "Parental Care and Clutch Sizes in North and South American Birds" (2000). Nebraska Cooperative Fish \& Wildlife Research Unit -Staff Publications. 58.

https://digitalcommons.unl.edu/ncfwrustaff/58

This Article is brought to you for free and open access by the Nebraska Cooperative Fish \& Wildlife Research Unit at DigitalCommons@University of Nebraska - Lincoln. It has been accepted for inclusion in Nebraska Cooperative Fish \& Wildlife Research Unit -- Staff Publications by an authorized administrator of DigitalCommons@University of Nebraska - Lincoln. 


\title{
Parental Care and Clutch Sizes in North and South American Birds
}

\author{
Thomas E. Martin, ${ }^{1,2 *}$ P. R. Martin, ${ }^{2}$ \\ C. R. Olson, ${ }^{2}$ B. J. Heidinger, ${ }^{2}$ J. J. Fontaine ${ }^{2}$
}

The evolutionary causes of small clutch sizes in tropical and Southern Hemisphere regions are poorly understood. Alexander Skutch proposed 50 years ago that higher nest predation in the south constrains the rate at which parent birds can deliver food to young and thereby constrains clutch size by limiting the number of young that parents can feed. This hypothesis for explaining differences in clutch size and parental behaviors between latitudes has remained untested. Here, a detailed study of bird species in Arizona and Argentina shows that Skutch's hypothesis explains clutch size variation within North and South America. However, neither Skutch's hypothesis nor two major alternatives explain differences between latitudes.

The dependent young of parents risk being eaten by predators. Variation in this predation risk may be an important source of natural selection on the behavior and life history strategies of parents (1), although it often has been overlooked. For example, the evolution of clutch size has long been attributed to food limitation rather than to nest predation in birds living in northern temperate climates (2). Yet nest predation may explain clutch size variation within (3) and among (4) latitudes. These contrasting views of food limitation versus nest predation could be resolved by an untested hypothesis proposed by Alexander Skutch in 1949 (5). Skutch argued that predators use parental activity to find nests, creating a predation cost that constrains the rate at which parents can visit nests to feed their young and thereby con-

${ }^{1}$ U.S. Geological Survey Biological Resources Division, 2Montana Cooperative Wildlife Research Unit, Avian Studies Program, University of Montana, Missoula, MT 59812, USA.

*To whom correspondence should be addressed. Email: tmartin@selway.umt.edu strains clutch size by limiting food delivery rates.

Skutch's hypothesis is important for three reasons. First, it proposes a mechanism whereby nest predation may create food limitation by constraining the rate of food delivery. This mechanism could then resolve alternative findings that food limitation (2) and nest predation (3) influence clutch size evolution in north temperate latitudes (1). Second, it suggests that parental care tactics (food provisioning) may be shaped by nest predation, a selection pressure that has been largely overlooked even though parental care is widely studied (6). Finally, this hypothesis is a widely invoked explanation for the small clutch sizes of tropical and Southern Hemisphere birds (4), which commonly lay about half as many eggs as their north temperate counterparts $(2,7)$. Yet the theory underlying this hypothesis remains undeveloped and untested.

Here we develop the theory underlying Skutch's hypothesis and test it with extensive data and original sampling methods in large, intact, north temperate and subtropical South- ern Hemisphere bird communities. In particular, we examine two questions: (i) Does nest predation influence parental care tactics and constrain food delivery? (ii) Do rates of food delivery and nest predation explain variation in clutch sizes among species within and between North and South America?

With respect to parental care, Skutch's hypothesis assumes that higher parental visitation rates incur a predation cost, so that individuals with greater activity suffer higher nest predation. This cost is expected to favor the evolution of reduced visitation rates in species or geographic regions where predation risk is higher. Parents should attempt to compensate for reduced visitation ( 8 ) by increasing the load of food brought per trip. However, as long as the food delivery rate (food load times visitation rate) is positively correlated with the visitation rate and the visitation rate is constrained by nest predation, then Skutch's hypothesis that nest predation constrains food delivery will be supported. Clutch size is expected to be determined by the rate at which food is delivered to the young. So if food delivery is constrained by nest predation and clutch size is determined by food delivery rate, then clutch size should decrease with nest predation.

We tested these predicted relationships by studying birds in large intact forests in Arizona and subtropical Argentina (9). We found and monitored 1331 nests in Argentina and 7284 nests in Arizona (10). Mean clutch size varied from 1.83 to 6.75 eggs among our study species and differed between latitudes; the clutch sizes of passerines at our Argentina site $(\bar{x} \pm \mathrm{SE}=$ $2.58 \pm 0.11, n=23$ species) were similar to those in the humid tropics [2.41 $\pm 0.06, n=$ 217 species (11)] but were much smaller than at our Arizona site (4.61 $\pm 0.24, n=21$ species). Smaller mean clutch sizes in southern latitudes could possibly reflect effects of taxa that are unique to these regions and that differ in their ecology from those of north temperate areas (12). To increase the strength of inference for our comparisons between latitudes, we con- 
ducted the first study to focus on species that were paired by phylogeny and ecology and represented a range of ecological types across multiple families (Table 1). Our eight pairs of species showed the classic pattern of much smaller clutch sizes in the south (Fig. 1), demonstrating that this pattern is not due to phylogeny and that these species provide a strong basis for comparative tests of nest predation and parental care between latitudes.

All of the parental care predictions underlying Skutch's hypothesis (5) are strongly supported by our results (Fig. 2). Individuals with increased parental activity incurred greater predation costs during incubation (13); three warbler species in Arizona made more trips at nests that were depredated than at nests that were successful during incubation (Fig. 2A). Such predation responses to parental activity depend on predators being diurnal and visually oriented (14). Major predators in Arizona (red squirrels, chipmunks, and Steller's jays) are diurnal and visually oriented in their hunting (15). Observations and video data in Argentina show diurnal birds as the most important predators, as has been noted in other studies in southern latitudes (16). Thus, diurnal predators are a reasonable source of selection on parental care behaviors.

Nest predation rates differ among species because of nest sites and habitat (3), and species that experience greater nest predation visited nests to feed nestlings at lower rates (Fig. 2B). Lower visitation rates were partly compensated by delivery of larger food loads per trip (Fig. 2C), but were insufficient to make up for the decrease in food delivery rate that occurs with decreased visitation rate (Fig. 2D). Consequently, nest predation constrained the rate of food delivery (Fig. 2E). Thus, data from North and South America provide strong support for Skutch's hypothesis that nest predation con-

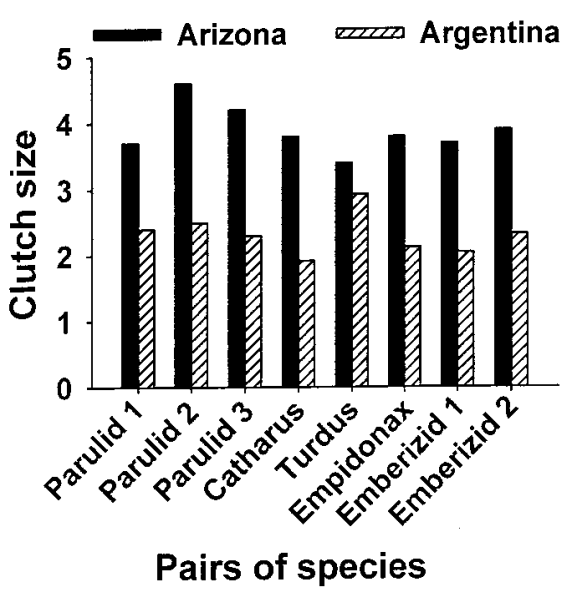

Fig. 1. Mean clutch sizes for species paired between Argentina and Arizona (26) were smaller in Argentina than in Arizona (paired $t$ test, $t=9.75, P<0.001$ ). Clutch sizes are based on nests where clutch sizes were confirmed after initiation of incubation. Species pair labels are defined in Table 1. strains parental care tactics and rates of food delivery.

Clutch size was positively related to food delivery rate within North and South America (Fig. 3A), as predicted by Skutch (5). Yet clutch sizes were even more strongly related to nest predation rates in each community (Fig. 3B), which suggests that nest predation may influence clutch size through additional mechanisms beyond Skutch's hypothesis. Thus, we provide some verification of Skutch's hypothesis (Figs.
2 and 3 ) while also confirming recent evidence (3) that nest predation is more important than food limitation for explaining clutch size variation within latitudes.

Although Skutch's hypothesis and nest predation can explain variation in clutch size within each community, they cannot explain differences between latitudes. Smaller clutch sizes in Argentina (Fig. 1) predict that nest predation should be greater and food delivery should be lower under Skutch's hypothesis. However,

Table 1. Our studies focused on species that were paired by phylogeny and ecology between a northern mixed forest in Arizona and a subtropical yunga forest in Argentina (9) and included large sample sizes. Species pair labels in the right column correspond to species labels in Figs. 1 and 4.

\begin{tabular}{|c|c|c|c|c|}
\hline Arizona species & $\begin{array}{l}\text { Nests } \\
(n)\end{array}$ & Argentina species & $\begin{array}{l}\text { Nests } \\
(n)\end{array}$ & $\begin{array}{l}\text { Species pair } \\
\text { label }\end{array}$ \\
\hline \multicolumn{5}{|c|}{ Parulidae (ground nest, foliage- or hover-glean/flush-chase) } \\
\hline Vermivora virginiae & 258 & Basileuterus signatus & 34 & Parulid 1 \\
\hline Vermivora celata & 472 & Basileuterus bivittatus & 91 & Parulid 2 \\
\hline Cardellina rubifrons & 271 & Myioborus brunniceps & 36 & Parulid 3 \\
\hline \multicolumn{5}{|c|}{ Turdidae (shrub/subcanopy-nesting, ground forage) } \\
\hline Catharus guttatus & 475 & Catharus dryas & 49 & Catharus \\
\hline Turdus migratorius & 351 & Turdus rufiventris & 130 & Turdus \\
\hline \multicolumn{5}{|c|}{ Tyrannidae (niche nest, flycatching/hover-glean) } \\
\hline Empidonax difficilis & $\begin{array}{l}423 \\
E m b\end{array}$ & $\begin{array}{l}\text { Empidonax euleri } \\
\text { (shrub nest, ground fo }\end{array}$ & 47 & Empidonax \\
\hline \multicolumn{5}{|c|}{ Emberizidae (ground nest, ground forage) } \\
\hline Junco hyemalis & 512 & Arremon flavirostris & 58 & Emberizid 2 \\
\hline
\end{tabular}

Fig. 2. (A) Visitation rate (trips per hour) of parents to the nest during incubation in Arizona (25) for three warbler species (vevi = Vermivora virginiae; caru $=$ Cardellina rubifrons; vece $=$ Vermivora celata) at nests that were depredated versus those that were successful during incubation. The number of trips was higher $(F=$ 41.2, $P<0.0001$; twofactor analysis of variance with species and nest fate as factors) at nests that were depredated than at nests that escaped predation during incubation. (B) The visitation rate of species to feed nest-

lings (27) decreased with increased daily nest predation rates (28). The relationship remained strong $(r=-0.90, P$ $<0.001$ ) when phylogeny was controlled (29). (C) Food load (30) decreased for parents of species that visit the nest more often. The illustrated correlation was not improved by controlling for body mass or latitude. The relationship remained significant $(r=-0.53, P=0.016)$ when phylogeny and body mass were controlled (29). (D) The food delivery rate (food load times visitation rate) increased with visitation rate among species; $r=0.84, P$ $<0.0001$ when phylogeny was controlled (29). (E) The food delivery rate decreased with increased daily nest predation rates (28) among species; $r=-0.79, P=0.001$ when phylogeny was controlled (29).
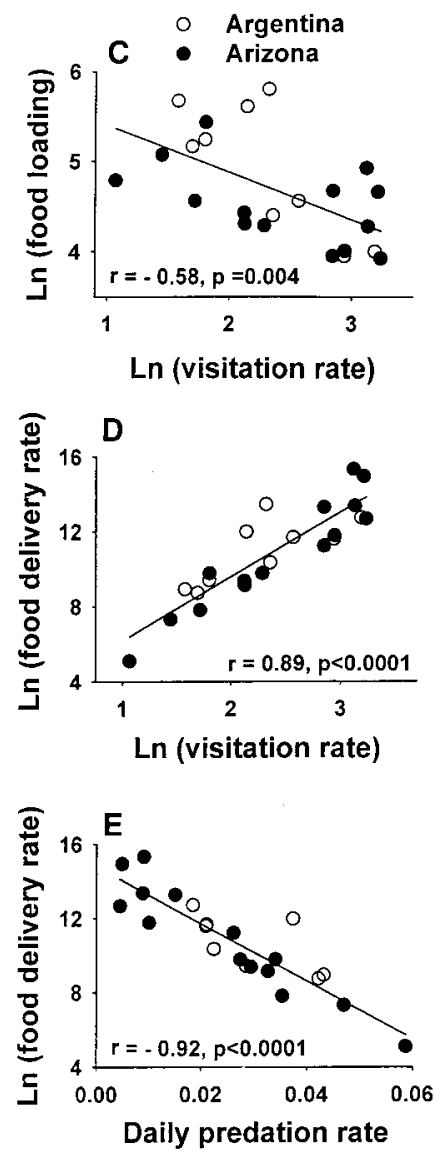


\section{R E P O R T S}
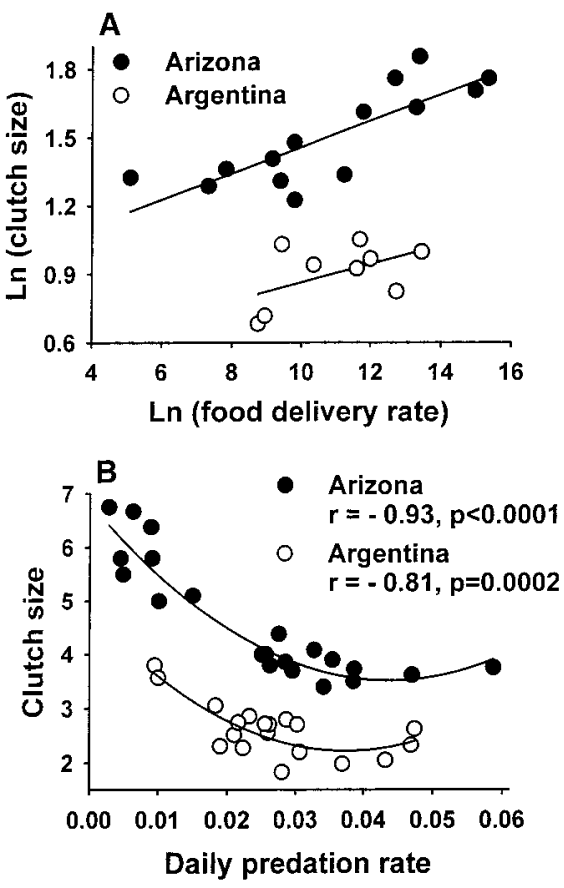

Fig. 3. (A) Clutch size relative to food delivery rate (food load times visitation rate). Clutch size is positively related to food delivery rate within each latitude $\left(r_{\mathrm{p}}=0.77, P<0.001\right.$; partial correlation is obtained from analysis of covariance with food delivery as a covariate and latitude as a main effect; $r=0.66, P=0.001$ when phylogeny is controlled). Clutch size is not related to food delivery rate between latitudes $(r=0.29, P=$ $0.20 ; r=-0.23, P=0.3$ when phylogeny is controlled). (B) Clutch size relative to daily nest predation rates (28). Clutch size is strongly related to nest predation within latitudes, but not between latitudes; for any given daily predation rate, clutch size was always smaller in Argentina than in Arizona. The Arizona data include seven hole-nesting species, whereas we only obtained clutch size data for two hole-nesting species in Argentina. The negative relationship in Argentina would increase with the addition of hole-nesters, because these species have lower predation rates and larger clutches than the open-nesters (31), as seen for Arizona. When phylogeny is controlled (29), the relationships remain significant (Arizona: $r=-0.66, P=0.003$; Argentina: $r=-0.50, P=$ 0.031).

predation rates were reduced in Argentina as compared with Arizona (Fig. 4A), and visitation rates for feeding young were nearly double in Argentina as compared with Arizona (Fig. 4B). Given the smaller number of young in Argentina (Fig. 1), the numbers of trips per nestling in Argentina were nearly triple those in Arizona (Fig. 4C). Moreover, food loading was higher than in Arizona (Fig. 4D), yielding substantially higher food delivery rates in Argentina than in Arizona (Fig. 4E). Such results contradict Skutch's hypothesis (5); the smaller clutch sizes in Argentina (Fig. 1) are associated with higher rather than lower food delivery rates (Fig. 4, B through E), so that clutch size was not related to food delivery

Fig. 4. Paired comparisons [paired $t$ tests (26)] controlled for phylogeny and ecology. (A) Daily predation rates (28) were lower in Argentina than in Arizona $(t=3.05, P$ $=0.011)$. (B) The rate (trips per hour) at which parents visited the nest to feed their young (27) was higher in Argentina than in Arizona $(t=2.70, P$ $=0.018)$. (C) The rate at which parents visited the nest to feed nestlings (27) was divided by the number of young to give the number of feeds per nestling per hour. This
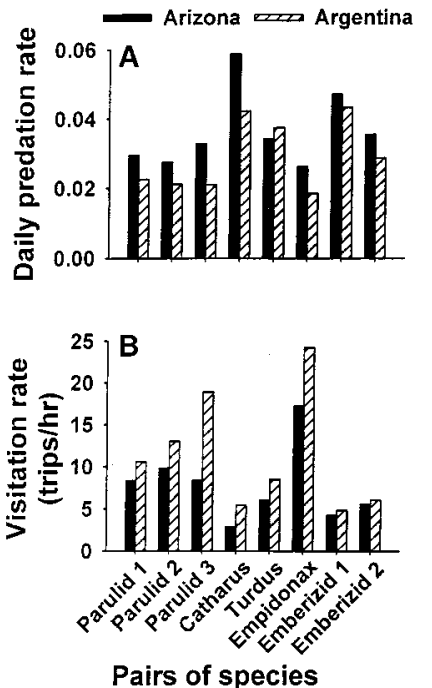

rate was greater in Argentina than in Arizona $(t=3.34, P=$ 0.008). (D) Food loads (amount of food) brought by parents per visit (30) were larger in Argentina than in Arizona ( $t=$ $2.21, P=0.035)$. (E) Food delivery rates, an index of the quantity of food delivered per hour, were greater in Argentina than in Arizona $(t=6.89, P<0.001)$. Species pair labels are defined in Table 1.
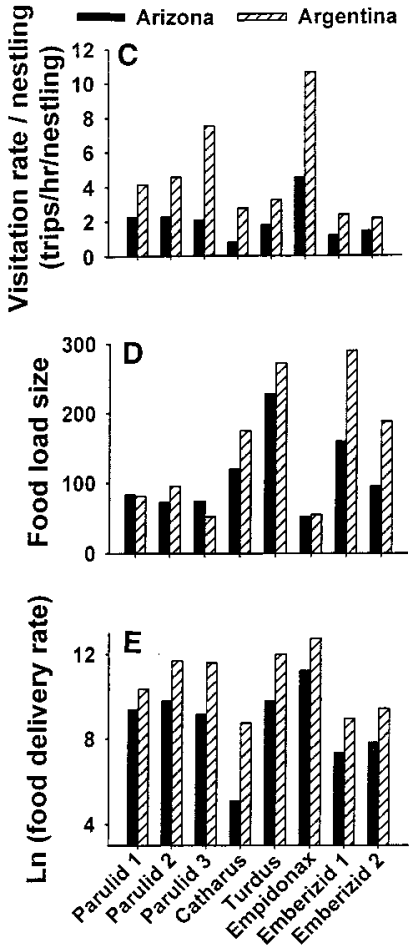

Pairs of species across latitudes (Fig. 3A). Thus, food delivery rate cannot explain differences in clutch sizes between latitudes.

Nest predation is not causing clutch size differences between latitudes via some other mechanism, because smaller clutch sizes in Argentina were not associated with higher nest predation rates (Figs. 3B and 4A). Thus, our results firmly reject nest predation as an explanation for small clutch sizes in Argentina, and this conclusion appears to apply broadly; nest predation rates at high-elevation tropical sites (17) are very similar to our Argentina rates and are not different from north temperate systems, as also found for some Australian sites $(7,18)$. Nestling feeding rates also are similar or even greater for high-elevation tropical species than for related species in Argentina (17). Yet clutch sizes at these elevations remain small $(11,17)$. Nest predation, therefore, cannot explain the small clutch sizes of high-elevation tropical sites either (8). Moreover, nest predation may have been overestimated in many southern studies because many were conducted in disturbed areas, which can cause increased nest predation from increased abundance of mesopredators (19). Taken together, all of these studies show that our results apply more broadly and that nest predation cannot explain small southern clutch sizes.

Given the inability of nest predation to explain latitudinal patterns, alternative hypotheses need greater attention. Food limitation and Ashmole's hypothesis (20) are widely invoked as two major alternatives (8). Ashmole's hypothesis assumes that low seasonality in the south maintains populations at or near carrying capacity, which causes increased food limitation (20). Both hypotheses thus depend on food limitation being greater in the south, which yields predictions that both nest visitation rates and food loading should be less in the south (8). However, we observed the opposite (Fig. 4), so that clutch size was not related to food delivery rate between latitudes (Fig. 3A). The greater delivery of food to fewer young in the south may reflect the effects of other factors such as lower food quality or increased parasite loads (21). Nonetheless, these two major alternative hypotheses for latitudinal patterns in clutch size are not supported. A less studied hypothesis proposes that small southern clutch sizes result from reduced adult mortality, favoring reduced reproductive effort and/or allocation of greater investment to fewer young $(8,11)$. The inability of the most widely invoked hypotheses to explain latitudinal patterns in clutch size illustrate that alternative hypotheses, such as adult mortality, deserve more attention, and that current theories of clutch size evolution need major revision.

References and Notes

1. T. E. Martin, Curr. Ornithol. 9, 163 (1992).

2. D. Lack, Ibis 90, 25 (1948); The Natural Regulation of Animal Numbers (Clarendon, Oxford, 1954); Ecological Adaptations for Breeding in Birds (Methuen, London, 1968); D. A. Roff, Evolution of Life Histories (Prentice-Hall, New York, 1992).

3. T. Slagsvold, Oecologia 54, 159 (1982); T. E. Martin, Ecol. Monogr. 65, 101 (1995); T. E. Martin and J. Clobert, Am. Nat. 147, 1028 (1996).

4. For data in the tropics, see Skutch $(5,11,17)$; D. W. Snow, J. Ornithol. 119, 227 (1978); G. Kulesza, Ibis 132, 407 (1990); and S. Sargent, Wilson Bull. 105, 


\section{R E P O R T S}

285 (1993). For data in the Southern Hemisphere, see G. L. MacLean, Cimbebasia 2, 163 (1974); D. Robinson, Emu 90, 40 (1990); and R. E. Major, Emu 91, 236 (1991).

5. A. F. Skutch, Ibis 91, 430 (1949).

6. T. H. Clutton-Brock, The Evolution of Parental Care (Princeton Univ. Press, Princeton, NJ, 1991)

7. I. Rowley and E. Russell, in Bird Population Studies: Relevance to Conservation and Management, C. M. Perrins, J.-D. Lebreton, G. J. M. Hirons, Eds. (Oxford Univ. Press, Oxford, 1991), pp. 22-44

8. T. E. Martin, J. Avian Biol. 27, 263 (1996).

9. The Arizona site was at $34^{\circ} \mathrm{N}$ in high-elevation $(2500$ $\mathrm{m}$ ) mixed conifer forests. This site is in the center of an extensive tract of forest with minimal human impact and containing large predators, including black bears, mountain lions, bobcats, coyotes, and foxes [T. E. Martin, Ecology 79, 653 (1998)]. The Argentina site was at $26^{\circ} \mathrm{S}$ in the center of El Rey National Park, a large park that contained large predators, including all large cats such as jaguars, mountain lions, and ocelots. The presence of large predators is important because their loss can allow increases in mesopredators that can increase nest predation rates (19).

10. Nests were located using parental behavior and checked every 1 to 4 days to determine the fate of clutches and whether parents were successful in fledging at least one young or failed because of predation or other causes, following the method of T. E. Martin and G. R. Geupel [J. Field Ornithol. 64, 507 (1993)].

11. A. F. Skutch, Ornithol. Monogr. 36, 575 (1985).

12. P. Harvey and M. D. Pagel, The Comparative Method in Evolutionary Biology (Oxford Univ. Press, Oxford, 1991).

13. Incubation was used for this test, because parents and young do not make noise during this period, allowing clear tests of the influence of parental activity. During the nestling period, the begging noise of young could influence predation rates independently of parental activity [D. Haskell, Proc. R. Soc. London Ser. B 257, 161 (1994); J. Briskie, P. R. Martin T. E. Martin, Proc. R. Soc. London Ser. B 266, 2153 (1999)].

14. J. J. Roper and R. R. Goldstein, J. Avian Biol. 28, 111 (1997).

15. T. E. Martin, Proc. Natl. Acad. Sci. U.S.A. 85, 2586 (1988); Nature 380, 338 (1996).

16. H. A. Ford, Emu 99, 91 (1991); R. E. Major et al., Oikos 69, 364 (1994); L. N. H. Taylor and H. A. Ford, Wildl. Res. 25, 587 (1998).

17. A. F. Skutch, Pacific Coast Avifauna no. 34 (1960); Publ. Nuttall Ornithol. Club no. 7 (1967); Publ. Nuttall Ornithol. Club no. 10 (1972); Publ. Nuttall Ornithol. Club no. 19 (1981)

18. T. B. Oatley, Ostrich 53, 206 (1982); R. A. Noske, Emu 91, 73 (1991); I. Rowley, M. Brooker, E. Russell, Emu 91, 197 (1991); A. Dyrcz, Emu 94, 17 (1994).

19. Y. Oniki, Biotropica 11, 60 (1979); J. P. Gibbs, Oikos 60, 155 (1993); J. Terborgh, Ecology 78, 1494 (1997).

20. N. P. Ashmole, Ibis 103, 458 (1963); M. L. Cody, Evolution 20, 174 (1966); J. C. Z. Woinarski, Proc. Ecol. Soc. Aust. 14, 159 (1985); Y. Yom Tov, Ibis 136, 131 (1994).

21. R. E. Ricklefs, Proc. Natl. Acad. Sci. U.S.A. 89, 4722 (1992).

22. T. E. Martin and C. K. Ghalambor, Am. Nat. 153, 131 (1999).

23. A. P. Møller and T. R. Birkhead, Evolution 48, 1089 (1994).

24. A. Purvis and A. Rambaut, Comp. Appl. Biosci. 11, 247 (1995); T. E. Martin and J. Clobert, Am. Nat. 147 1028 (1996).

25. From 1993 to 1998 , birds were videotaped during both incubation and nestling periods with video cameras for the first 6 hours of the day, beginning 0.5 hours before sunrise, as described in (22). This protocol standardized both time of day and sampling duration. All video recordings during the nestling period were made within 1 to 2 days of the time when primary feathers broke their sheaths to control for stage of development. The number of trips per hour was averaged over the 6 hours of monitoring for each nest (22).

26. This study was designed to allow paired comparisons of traits between latitudes (Figs. 1 and 4) using paired sample $t$ tests. Paired comparisons are a strong way to compare between latitudes because they can control for both phylogeny and ecology (Table 1). Paired comparisons use contrasts between extant species that do not require estimates of branch lengths and make no assumptions about modes of character evolution $(12,23)$. When phylogenetic paths cross, the average for nodes that do not cross is used (24). As a result, the two Basileuterus species are averaged and compared to the average of the two Vermivora species for all paired comparisons, yielding six paired comparisons.

27. Visitation rates were quantified as described in (25). The number of trips per hour was calculated for each nest and then averaged across all nests within a species to obtain the mean for each species. A minimum of six nests ( 6 hours each) was used (22), but many more nests were sampled per species in most cases.

28. Daily predation rates represent the probability per day that a nest is depredated [G. L. Hensler and J. D. Nichols, Wilson Bull. 93, 42 (1981)]. Only species with $n>20$ nests were used.

29. Relationships among species were examined while controlling for phylogeny by means of independent contrasts $(3,12)$. Controlling for phylogeny is important because behaviors may be similar in closely related species (12). A phylogeny was constructed using recent phylogenetic information (3). We calculated linear contrasts for each node in the phylogeny using the Comparative Analysis by Independent Contrast program [A. Purvis and A. Rambaut, Comp. Appl. Biosci. 11, 247 (1995)]. These independent contrasts were used to examine correlations that were forced through the origin (12).

30. Food loading was measured as the size of visible food in the bills of parents arriving at the nest of nestlings that had broken their primary feather sheaths within 1 to 2 days. A small $(4 \mathrm{~cm})$ remote telephoto camera lens (MicroVideo) was placed within $1 \mathrm{~m}$ of nests to allow high-resolution closeup video images and measurement of food loading. The load size was estimated by measuring bill size and using it to calibrate the area of digital video images of load size obtained from video footage using GRABITII. Area was used to estimate load size.

31. Hole-nesting species typically have lower predation rates and larger clutches than do open-nesting birds (3). Five species in Argentina that nested in holes or in complex protected nests (Piculus rubiginosus, Synallaxis superciliosa, Syndactyla rufosuperciliata, Trogolodytes aedon, and Troglodytes solstitialis) had daily predation rates from 0 to $0.018(\bar{x}=0.0066 \pm$ $0.003)$, which is much lower than rates for the opennesting species (Fig. 3B). However, we lacked clutch size data for three of these species.

32. We thank C. Ghalambor, J. McKay, J. Tewksbury, K. Marchetti, T. Price, and two anonymous reviewers for helpful comments; many field assistants for their help in collecting the field data; the Arizona Game and Fish Agency and Coconino and Apache-Sitgreaves National Forests for their logistical support of the Arizona work; and the Laboratorio de Investigaciones Ecologicas de las Yungas, M. Rouges, P. Marconi, and El Rey National Park staff for logistical support of the Argentina work. Supported by grants from NSF (DEB-9527318, DEB-9707598, and DEB9900343), the U.S. Geological Survey Biological Resources Division, and the International Program of the U.S. Fish and Wildlife Service.

7 October 1999; accepted 23 December 1999 